\title{
Time Estimation in Developmental Dyslexia: An Experimental Investigation
}

\author{
Azizuddin Khan 1,2, Abdalla Abdal-hay33, Tabassum Qazi', Claudio López Calle², \\ Ruth Clavijo Castillo ${ }^{2}$ \\ ${ }^{1}$ Psychophysiology Laboratory, Department of Humanities and Social Sciences, Indian Institute of Technology \\ Bombay, Mumbai, India \\ ${ }^{2}$ Facultad de Psicología, Universidad de Cuenca, Cuenca, Ecuador \\ ${ }^{3}$ Engineering Materials and Mechanical Design, Faculty of Engineering, South Valley University, Qena, Egypt \\ ${ }^{4}$ Department of Psychology, S.N.D.T University, Churchgate, Mumbai, India \\ Email:khanaziz@iitb.ac.in, azizuddin.khan@ucuenca.edu.ec, abda555@jbnu.ac.kr, tabbu11@gmail.com, \\ claudio.lopez@ucuenca.edu.ec, ruth.clavijo@ucuenca.edu.ec
}

Received 12 July 2014; revised 12 August 2014; accepted 12 September 2014

Copyright (C) 2014 by authors and Scientific Research Publishing Inc.

This work is licensed under the Creative Commons Attribution International License (CC BY).

http://creativecommons.org/licenses/by/4.0/

(c) (i) Open Access

\begin{abstract}
Time estimation is the ability to judge the duration or apprehend the passage of time by the order of occurrence of experience or by physiological rhythm (Fraisse, 1984). It plays quite a significant role in language disorder especially developmental dyslexia. It is characterized by deficits in phonological processing abilities. However, it is unclear what the underlying factors for poor phonological abilities or speech sound representations are. The deficit in phonological processes has been for the processing of paired tones or temporal sequences different when relatively short time intervals are used in individuals with dyslexia compared to typical readers. This paper presents the results of a study that was undertaken to determine the effects of method of time judgment, and paradigm on dyslexic and atypical readers. An experiment was conducted using 115 children (age: $M=12.23$ years, $S D=1.30$ ), 51 dyslexics and 64 typical readers. The data were obtained through the method of verbal estimation and reproduction. Analysis of variance was used to analyse the data. Time judgments data were analyzed using directional error. For directional error, all the main effects and few interactions were significant. Children with dyslexia showed more errors in time estimation $(M=0.59, S D=0.52)$ as compared to typical readers $(M=0.83, S D$ $=0.74$ ). Estimation of duration under the prospective paradigm was more accurate than under the retrospective paradigm for both dyslexics and typical readers. However, dyslexics were more error prone as compared to typical readers. Time judgment was accurate under verbal time estimation as compared to reproduction method.
\end{abstract}

\section{Keywords}

Duration, Language Disorder, Phonological Deficit, Typical Reader 


\section{Introduction}

Developmental dyslexia is a language pathology that hinders reading and writing acquisition of around $8 \%$ to $10 \%$ of the children all over the world [1]. Dyslexic children are generally impaired in their abilities to discriminate sounds (phonemes) of their languages (for instance, "ba" and "da"), or to discover outliers in sequences of words (e.g. "sapin", lapin", and "crayon"). A commonly accepted hypothesis is that dyslexic children encounter difficulties in reading and writing because they are impaired in their abilities to discriminate basic sound units of spoken language. Thus, phonological dyslexia may be a consequence of a deficit in the conversion between sounds (phonemes) and letters (graphemes). Dyslexic children would be impaired in their abilities to segment and discriminate the sequence of sounds in a spoken language, that is, in their "phonological awareness" [2]. The phonological loop evolved to facilitate the acquisition of language [3]. The segmentation of text into grapheme is considered one of the indicators of acquisition of reading ability. Its capacity is a good predictor and indicator of the ability of children and adults to learn new language [4]. Research has indicated that the conversion of the written word image into its phonological equivalent in the brain is crucial in the normal process of reading fluently. Failure to develop an association between letter and sound is a major cause of reading and spelling impairment in many or most instances of developmental dyslexia.

The bulk of research in the past decade has investigated an approach of the phonological deficit hypothesis in dyslexics. Phonological awareness is a skill that is picked up initially just by listening to one's own language. It is an auditory skill. Phonological awareness enables the listener to recognize, identify, and manipulate basic language sounds (phoneme segmentation, blending, and deletion). Babies begin to develop phonological awareness as soon as they absorb and acquire the sounds of their native language. The child hears the sounds of words and attempts to repeat them as heard. According to the phonological deficit hypothesis, dyslexics have a difficult time with written language because they have an impaired ability to deconstruct written words into phonemes and therefore it prevents word identification. Several studies since the early 1990s have demonstrated that if dyslexic children are asked to divide specific words into phonemes and then delete a specific phoneme, they show phonological deficits. For example, if a child is asked to say "rock" without the "r" sound, dyslexic children as compared to non dyslexics have greater difficulty with this phoneme deletion task and are unable to do it.

Deficits in phonological processing are seen in the majority of children with dyslexia. The phonological deficit theory of dyslexia has received support from studies of dyslexia across the life span. A substantial number of studies of adults with a developmental history of dyslexia have reported persisting deficits in phonological awareness and in phonological processing tasks [5]-[8]. It affects the acquisition of phonic skills in reading and spelling so that unfamiliar words are frequently misread.

The cerebellum is critically involved in the automatisation of any skill-either motor or cognitive. The cerebellum is a very densely packed and deeply folded sub cortical brain structure situated at the back of the brain and also called as hind-brain. Traditionally, cerebellum is considered to be a motor area. Ivry and Keele [9] have suggested that cerebellum plays an important role not only in motor control but also in the perception of time. The human cerebellum is linked not only to the frontal motor areas but also to the frontal cortex and Broca's areas which is responsible for understanding the language and speak. One theory that has gained attention in the past is the cerebellar theory of dyslexia. As dyslexic children have problems with skill automatisation, cerebellar deficit hypothesis is proposed. The cerebellar deficit hypothesis says that cerebellar abnormality is a cause of difficulties suffered by dyslexia children. There is evidence that the cerebellum of people with dyslexia is mildly dysfunctional and numbers of cognitive difficulties occur from this dysfunction and consequently difficulty in speech production [10]. Dysfunction speech production results in deficient phonological processing and representation.

Dyslexia, cerebellum and time perception seem to be closely related to each other. Time perception is the ability to judge the duration or apprehend the passage of time by the order of occurrence of experience or by psychological rhythm. Our perception of time depends upon the multiple processes that enable anticipation of events. Deficits in the time perception have been found in children with dyslexia. None of the sensory organ is responsible for perceiving time. Two lines of thought can be described that affect subjective experience of time. Cognitive theories suggest that temporal experience of passage of time depends upon the nature and extent of the cognitive processing performed by a person during a given interval. The biological approach says that people have internal cycles that can be used to measure time.

There are only few studies investigating time perception among dyslexic's children. I have come across only two studies focusing time perception in dyslexia. Nicolson, Fawcett, and Dean [11] in their study found that 
dyslexics performed worse on time estimation task as compared to normal control group. There were three dyslexics mean age 9, 14, and 18 years and same age group of control group. There was one standard stimulus of duration $1200 \mathrm{~ms}$ and eleven other identical stimuli of longer and shorter duration (for example, 1220, 1240 up to $2000 \mathrm{~ms}$ for longer duration and from 1180 to $400 \mathrm{~ms}$ for shorter duration. The results showed that there was significantly deteriorated performance by dyslexic group but not by the control group. Similarly, Gooch, Snowling and Hulme [12] conducted a study on dyslexics and ADHD children. They found that performance of dyslexics was impaired as compared to normal children. In both the studies, short durations were assessed among dyslexics and normal control group. In the current study, both long and short duration were used. Further, time estimation can be done either prospectively as well as retrospectively.

Hicks, Miller and Kinsbourne [13] reported that under the prospective time estimation paradigm, subjects were explicitly told in advance that they would be required to judge the duration of an interval. This procedure presumably motivates subjects to monitor the time passing by and to attend to any available temporal cues [14]. In contrast, subjects tested under the retrospective paradigm are not given any warning about time judgment at the start of the interval. These subjects are unexpectedly asked to judge the duration of the interval after it has already passed by. Subjects tested under retrospective conditions are presumed to process temporal information in a more incidental and unreliable fashion.

Time judgment method also affects time estimation [15]. In the present experiment, verbal estimation and reproduction methods were utilized. In the verbal estimation method, a person is asked to use conventional time units to subjectively estimate an experienced duration. Verbal estimation has some drawbacks because it assumes that the translation between conventional units and subjective duration is reliable. In the reproduction method, the person experienced certain duration and was then asked to delimit a subjective duration to estimate it. Although reproduction did not require a translation involving conventional duration units, the method had another drawback: if the rate of physiological and cognitive processes varied from one individual to another, the same rate sub served an individual's experiencing the target duration and reproduced the duration oral information in a more incidental and unreliable fashion.

The next factor which influences time estimation is actual duration of time. Short duration is generally overestimated while long duration is underestimated [16]. There are very few researches using long duration. It should be noted that [17] also reported overestimation of the interval for short duration. But there is no consistent result whenever various other parameters are included such as paradigm and task demands.

The experiment was designed with the following specific objectives. The first objective was to compare prospective and retrospective time judgment among dyslexics and normal control group. In this study it was expected that prospective time judgment would be more accurate than retrospective time judgment. The second objective was to assess the effect of duration on time estimation in dyslexics and normal control. The third objective was to assess method of time judgment method on time estimation. Overall, the main objective was to investigate time estimation among dyslexics population.

\section{Method}

\subsection{Subjects}

One hundred and thirty subjects participated in the experiment. They were class V to class IX students with the mean age of 11.21 . Out of 115,51 subjects were diagnosed as learning disabled. 64 subjects were students without any disability and drawn from Mumbai suburban school.

\subsection{Design}

The experiment employed ANOVA designs, which are described below after a brief description of the variables. The design of the first part of the experiment was a 2 (Group: Dyslexic, and Normal Control; between subjects) $\times 2$ (Paradigm: retrospective and prospective; between subjects) $\times 2$ (Method of judgment: verbal time estimation and reproduction; within subjects) split-plot design. The design of the second part of the experiment was a 2 (Group: Dyslexic, and Normal Control; between subjects) $\times 2$ (Paradigm: retrospective and prospective; between subjects) $\times 2$ (Actual duration: short- and long-duration; within subjects) split-plot design.

Time judgments were transformed into measures representing directional error as explained below.

For the measure of directional error, data were transformed into ratio scores by dividing each judgment by the 
corresponding actual elapsed time using equation.

$$
\text { Directional error }=\frac{\text { Judged time }}{\text { Actual time }}
$$

In the experiment, there was one actual elapsed durations for long duration, i.e., $150 \mathrm{~s}$. In the transformed data set, a value of directional error less than unity (1) represents a judgment shorter than the actual duration (underestimation), whereas the value greater than unity represents a judgment longer than the actual duration (overestimation). A directional error with a value " 1 " represents perfect estimation.

\subsection{Stimulus Material}

The stimulus material consisted of a list of 30 items including names of 15 substances used for flavouring food (taken from List 25, Page 20 of Battig and Montague [18] and 15 fruit names (List 16, Page 14 of Battig and Montague [18]).

\subsection{Instrumentation and Presentation of Stimulus Material}

A computer program using visual basic was developed (1) to record personal information of the subjects, (2) to present the items to the subjects on a computer screen, one after the other, in a controlled manner, and (3) for recording subjects' responses. A window appeared on the screen. The first window (Display 1) was designed to record personal details of the subject. After completing the personal details, the subject clicked the icon "Next" on the screen which opened a new window (Display 2). The new window contained the identity number of the subject, identification category of the stimulus item shown as " $\mathrm{F}$ " on the screen, a blank space for the appearance of items below the id number, a "Start" icon and "Click to Your Choice" icon on the right side of the "blank space" icon. When the first item on the list appeared in the blank space on the screen, the subject clicked the 'Start' icon and a screen opened as shown in Display 3. The items appeared on the screen one after the other. Each item remained on the screen for the duration of $2 \mathrm{~s}$. The inter-item interval was kept constant at $3 \mathrm{~s}$. After the disappearance of the last item on the screen, the screen was blank for $3 \mathrm{~s}$ and then the instruction appeared on the screen for the subject to record (1) total estimated time from the appearance of first word on the list to the disappearance of the last word, (2) duration between two consecutive words, and (3) flashed duration of a word (appearance time) in the blank window provided for this purpose (Display 4). A left click of the mouse on the "Save" icon on the screen (Display 4) saved the data and automatically closed the window. Immediately following this, a new window (Display 5) automatically opened for the reproduction of the actual duration. Proper instructions appeared on the screen for the subject to record reproduced time (Display 5). At this stage the "Back" icon was non-operational.

To summarize, an item appeared for $2 \mathrm{~s}$, with inter-item interval of $3 \mathrm{~s}$. A blank interval of $3 \mathrm{~s}$ was included toward the end of the list. Thus, actual duration for presenting the entire list was $150 \mathrm{~s}$ (appearance time of individual item: $2 \mathrm{~s}$ ).

There were two levels of actual duration of time interval: $2 \mathrm{~s}$, with an interval of $3 \mathrm{~s}$ between two consecutive items. The actual time taken for the presentation of all 30 items $2 \mathrm{~s}$ duration of interval was 150 seconds. Each subject had to estimate time interval for both short duration and long duration.

\subsection{The Task}

Subjects participated in the experiment individually. They were required to use the mouse for giving responses. As described above, a computer program was developed to record the estimated time. The task of the subjects varied depending on the condition of the experiment. In the low cognitive load condition, subjects had to concentrate on items which popped up on the screen. In the medium cognitive load condition, subjects had to identify items belonging to fruit names by clicking the mouse on the appropriate place provided on the screen; they had to do nothing if an item was not a fruit name. In the high cognitive load condition, subjects had to memorize each item which appeared on the screen. However, there was no test of memory.

\subsection{Procedure}

Each subject was tested individually. The subject was seated in front of the color monitor of a computer. The 
subject first completed the personal details. The researcher then gave specific instructions regarding the task to be carried out depending on the treatment condition of the experiment in which the subject was participating. Instructions for each treatment combination are presented in the instruction section. The subject was told to respond by clicking the mouse of the computer as described below.

Depending on the experimental treatment in which a subject was participating, the subject was instructed to pay attention to presented items (low cognitive load), identify if an item was a fruit name (medium cognitive load), or memorize the items (high cognitive load).

Half of the subjects were tested under prospective paradigm condition and they were informed at the beginning of the experiment that they would be asked to judge the duration of the task interval after its completion and that they should monitor the time passed by. The remaining subjects were tested under the retrospective paradigm and were not given any advance information about time monitoring and estimation task.

Subjects provided time judgments through the methods of verbal estimation and reproduction. They were urged to be as accurate as possible in making these judgments. When the presentation of the entire list of the items was over, subjects were asked to provide (a) verbal estimate of how long a particular item appeared on the screen during the presentation of items, (b) time interval between two consecutive items, and (c) total time taken for presentation of all the items.

In the case of reproduction, the subjects were asked to reproduce the time by clicking the left button of the mouse twice to reproduce the duration that they judged to be equal to that of the total task duration: at the first click of the mouse, the computer started encoding passage of time and when the subject clicked the mouse again, time encoding was terminated. Thus the computer recorded the subject's reproduced time.

\section{Results}

Unless otherwise stated, only effects significant beyond at or 0.05 levels are described. The mean and standard deviation scores for each question type are shown in Table 1 and Figure 1.

Two analyses were conducted. First analysis was 2 (Group: Dyslexia vs. Normal control) $\times 2$ (Paradigm: Prospective vs. Retrospective) $\times 2$ (Method: Verbal estimation vs. Reproduction) mixed factorial design, last factor being within design. Analysis of variance revealed that all the main effects were significant except cue as shown in Table 2. Method (Verbal estimation vs. Reproduction): $\left\{\mathrm{F}(1,111)=12.69, \mathrm{p}<0.001, \eta^{2}=0.10\right\}$, Paradigm (Prospective vs. Retrospective) $\left\{\mathrm{F}(1,111)=3.75, \mathrm{p}<0.005, \eta^{2}=0.0 .03\right\}$, Disorder (Developmental dyslexia vs. Control Group) $\left\{\mathrm{F}(1,111)=5.47, \mathrm{p}<0.05, \eta^{2}=0.05\right\}$. A significant interaction was obtained between method and paradigm $\left\{\mathrm{F}(1,111)=5.79, \mathrm{p}<0.01, \eta^{2}=0.05\right\}$. Further, the interactions between paradigm $\times$ disorder $\left\{\mathrm{F}(1,111)=5.47, \mathrm{p}<0.07, \eta^{2}=0.03\right\}$ was also near significant as shown in Table 2 and Figure 2. However, no other interaction was significant.

A second analysis employed 2 (Paradigm: retrospective and prospective; between subjects) $\times 2$ (Disorder: Dyslexia vs. Normal control; between subjects) $\times 2$ (Duration: Long vs. Short; within) designs. The analysis variance showed that main effect of duration $\left\{\mathrm{F}(1,111)=68.16, \mathrm{p}<0.001, \eta^{2}=0.38\right\}$. No other main effect was significant. The interactions between duration $\times$ paradigm $\left\{\mathrm{F}(1,111)=5.38, \mathrm{p}<0.05, \eta^{2}=0.05\right\}$ and duration $\mathrm{x}$ disorder $\left\{\mathrm{F}(1,111)=6.43, \mathrm{p}<0.01, \eta^{2}=0.06\right\}$ were also significant in Table 3 and Figure 3 .

\section{Discussion and Conclusions}

The experiment was designed to assess the time estimation ability among dyslexics and normal control group.

Table 1. Means and (Standard Deviation) of time estimation error as a function of method (Verbal estimation vs. Reproduction), Paradigm (Prospective vs. Retrospective paradigm) and Group (Dyslexia vs. Normal control).

\begin{tabular}{|c|c|c|c|c|c|c|}
\hline \multirow[b]{3}{*}{ Group } & \multicolumn{6}{|c|}{ Time estimation error } \\
\hline & \multicolumn{3}{|c|}{ Verbal estimation } & \multicolumn{3}{|c|}{ Reproduction } \\
\hline & $\begin{array}{c}\text { Prospective } \\
\text { paradigm }\end{array}$ & $\begin{array}{l}\text { Retrospective } \\
\text { paradigm }\end{array}$ & Total & $\begin{array}{c}\text { Prospective } \\
\text { paradigm }\end{array}$ & $\begin{array}{c}\text { Retrospective } \\
\text { paradigm }\end{array}$ & Total \\
\hline Dyslexia & $0.82(0.60)$ & $0.38(0.31)$ & $0.60(0.46)$ & $0.56(0.30)$ & $0.43(0.31)$ & $0.50(0.31)$ \\
\hline Normal Control & $0.92(0.89)$ & $0.81(0.62)$ & $0.87(0.76)$ & $0.54(0.28)$ & $0.63(0.31)$ & $0.59(0.30)$ \\
\hline Total & $0.87(0.75)$ & $0.50(0.39)$ & $0.73(0.61)$ & $0.56(0.31)$ & $0.53(0.30)$ & $0.55(0.31)$ \\
\hline
\end{tabular}




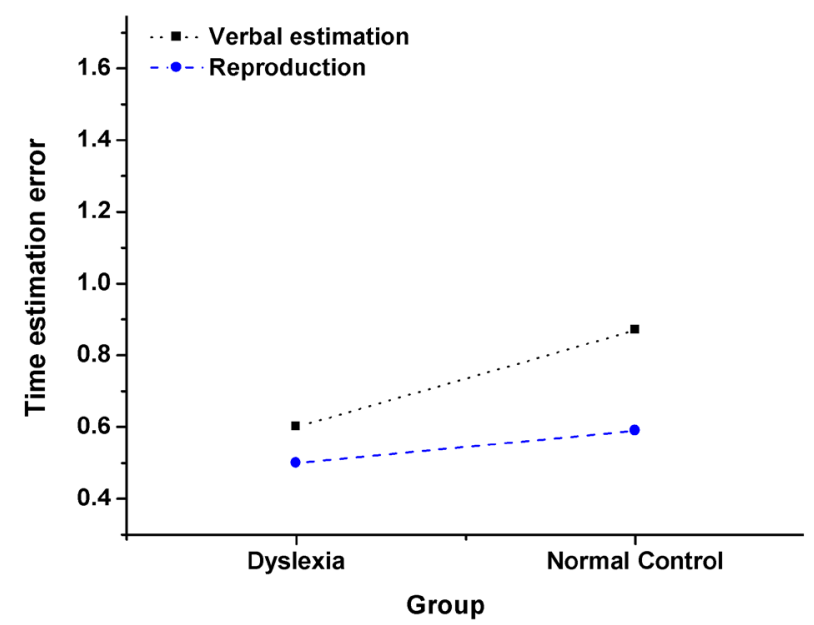

Figure 1. Directional error as function of method of time estimation (Verbal time estimation vs. Reproduction) and group Dyslexia vs. Normal control).

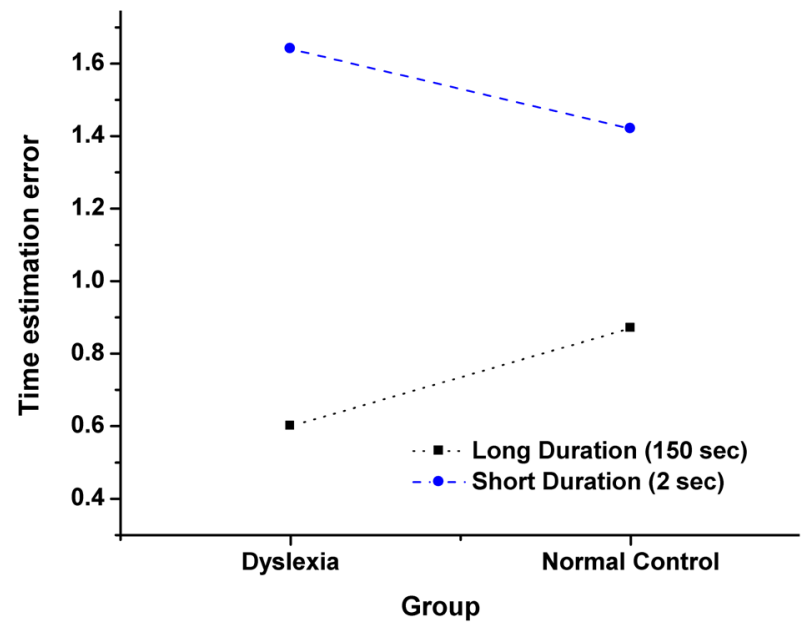

Figure 2. Directional error as function of duration of time estimation (Long duration vs. Short duration) and group (Dyslexia vs. Normal control).

Table 2. Summary of analysis of variance of performance scores on Disorder (Dyslexic vs. Normal control), Paradigm (Prospective vs. Retrospective), and Method (Verbal estimation vs. Reproduction).

\begin{tabular}{ccccccc}
\hline Source & SS & df & Mean square & F & Sig. & Partial eta squared \\
\hline Between subjects & & & & & & 0.03 \\
Paradigm & 1.24 & 1 & 1.24 & 3.75 & 0.05 & 0.05 \\
Disorder & 1.82 & 1 & 1.82 & 5.47 & 0.05 & 0.03 \\
Paradigm $\times$ Disorder & 1.08 & 1 & 1.08 & 3.25 & 0.07 & 0.10 \\
Error & 36.85 & 111 & 1.08 & & & 0.05 \\
Within subjects & & & & & & \\
Method & 2.07 & 1 & 2.07 & 0.001 & 0.01 & \\
Method $\times$ Paradigm & 0.99 & 1 & 0.99 & 5.79 & & \\
Error & 18.09 & 111 & 0.16 & & & \\
\hline
\end{tabular}


Table 3. Means and (Standard Deviation) of time estimation error as a function of duration (Long duration vs. Short duration), Paradigm (Prospective vs. Retrospective paradigm) and Group (Dyslexia vs. Normal control).

\begin{tabular}{|c|c|c|c|c|c|c|}
\hline \multirow{3}{*}{ Group } & \multicolumn{6}{|c|}{ Time estimation error } \\
\hline & \multicolumn{3}{|c|}{ Long duration (150 sec) } & \multicolumn{3}{|c|}{ Short duration (2 sec) } \\
\hline & $\begin{array}{l}\text { Prospective } \\
\text { paradigm }\end{array}$ & $\begin{array}{l}\text { Retrospective } \\
\text { paradigm }\end{array}$ & Total & $\begin{array}{c}\text { Prospective } \\
\text { paradigm }\end{array}$ & $\begin{array}{c}\text { Retrospective } \\
\text { paradigm }\end{array}$ & Total \\
\hline Dyslexia & $0.82(0.60)$ & $0.38(0.31)$ & $0.60(0.46)$ & $1.60(0.97)$ & $1.68(0.99)$ & $1.64(0.98)$ \\
\hline Normal control & $0.92(0.89)$ & $0.81(0.62)$ & $0.87(0.76)$ & $1.29(0.79)$ & $1.54(1.22)$ & $1.42(1.01)$ \\
\hline Total & $0.87(0.76)$ & $0.60(0.39)$ & $0.73(0.61)$ & $1.45(0.88)$ & $1.61(1.11)$ & $1.53(1.00)$ \\
\hline
\end{tabular}

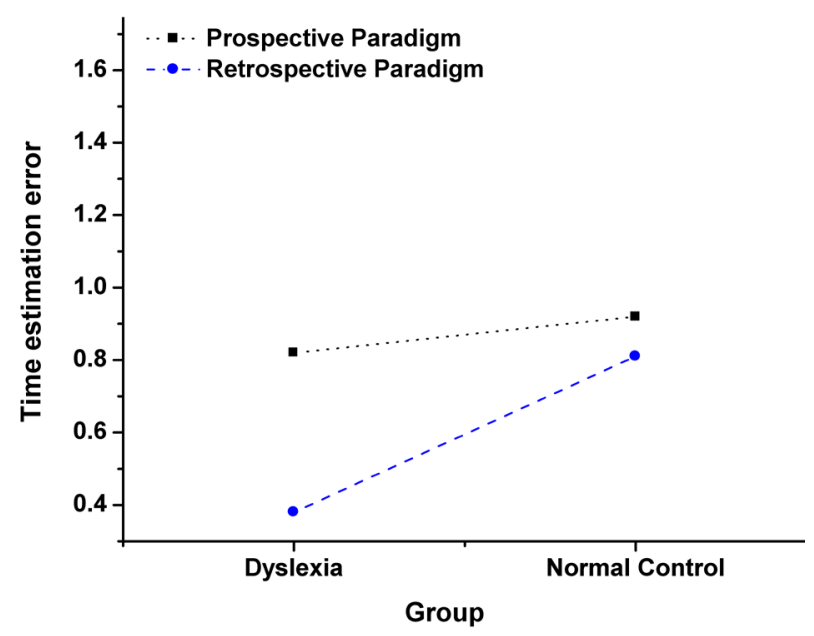

Figure 3. Directional errors as function of duration of Paradigm (Prospective vs. Retrospective paradigm) and group (Dyslexia vs. Normal control).

The data were converted into directional errors. As results showed, there were more errors in time estimation among dyslexics $(\mathrm{M}=0.60, \mathrm{SD}=0.46)$ than normal control group $(\mathrm{M}=0.87, \mathrm{SD}=0.76)$ under verbal estimation. Similar result was obtained under reproduction method of time estimation as shown in Table 1. Dyslexics performed worse under retrospective paradigm $(\mathrm{M}=0.41, \mathrm{SD}=0.31)$ as compared to prospective paradigm ( $\mathrm{M}$ $=0.69, \mathrm{SD}=0.45)$. It was expected because participants under prospective paradigm knew in advance that they were supposed to estimate passage of time. This result is consistent with the findings of Hicks et al. [13]. Attention to time-in-passing can be cited as the reason for relatively accurate time estimation by the subject under prospective paradigm [17] [19]-[21]. According to their view, subjective duration increases with the subject's attention to time. As subject pays attention to time, it results in the storage of subjective temporal units. On the other hand, subjects under retrospective paradigm process temporal information in an incidental manner. Since subjects under retrospective paradigm had no prior knowledge about the time estimation task, they might have retrieved temporal information from their memory. This, therefore, could be the probable reason for retrospective time judgment being less precise. Similarly, there was significant difference between verbal estimation $(\mathrm{M}=$ $0.60, \mathrm{SD}=0.46)$ and reproduction method $(\mathrm{M}=0.50, \mathrm{SD}=0.31)$ of time estimation.

In the analyses, verbal estimations of time were found to be more accurate than time reproductions. This finding is inconsistent with most of the earlier findings [17] [22]. The finding that verbal estimation produces more accurate judgments as compared to reproduction method can be explained on the basis of the task involvement and the gap between the presentation and reproduction of temporal information. Reproduction method requires active involvement in the task. This might have resulted in more errors in time judgment. In addition to this, the waiting period during the gap could have distracted the subjects from paying attention to time. Earlier studies [23]-[27] utilized only short duration for comparing verbal and reproduction methods. The present study employed long duration (150 s, $210 \mathrm{~s}$ and $270 \mathrm{~s})$ to determine the effect of verbal and reproduction 
method on time judgment. It is quite possible that for longer duration factors such as task involvement might be important. There is a need for further research using both short- and long-duration to determine the exact role of duration in reproduction method.

The present study employed time judgment of both short and long durations. There were very few studies that had employed long duration for prospective paradigm and short duration for retrospective paradigm among normal population. There is not a single study to investigate prospective and retrospective paradigm among dyslexics population. Short duration was overestimated $(\mathrm{M}=0.60, \mathrm{SD}=0.46)$ whereas long duration was underestimated $(\mathrm{M}=1.64, \mathrm{SD}=0.98)$ among dyslexics. Normal control's performance on short $(\mathrm{M}=1.42, \mathrm{SD}=1.01)$ and long duration $(\mathrm{M}=0.87, \mathrm{SD}=0.76)$ was under and over-estimated respectively. However, dyslexic's performance was more deteriorated as compared to normal control. As far as time estimation of long duration is concerned, dyslexics performance was more accurate under prospective paradigm $(\mathrm{M}=0.82, \mathrm{SD}=0.60)$ as compared to retrospective paradigm $(\mathrm{M}=0.38, \mathrm{SD}=0.31)$. Normal control's performance under prospective (M $=0.92, \mathrm{SD}=0.89)$ and retrospective paradigm $(\mathrm{M}=0.81, \mathrm{SD}=0.62)$ was more accurate as compared to dyslexics population. Time estimation of short duration was over estimated by dyslexics and control group under prospective $(\mathrm{M}=1.60, \mathrm{SD}=0.97)$ and retrospective paradigm $(1.68, \mathrm{SD}=0.99)$. However, errors of time estimation of dyslexics were more acute than normal control group.

This result is consistent with the findings of Hicks et al. [13]. Attention to time-in-passing can be cited as the reason for relatively accurate time estimation by the subject under prospective paradigm [17] [19]-[21]. According to their view, subjective duration increases with the subject's attention to time. As subject pays attention to time, it results in the storage of subjective temporal units. On the other hand, subjects under retrospective paradigm process temporal information in an incidental manner. Since subjects under retrospective paradigm had no prior knowledge about the time estimation task, they might have retrieved temporal information from their memory. This, therefore, could be the probable reason for retrospective time judgment being less precise.

Both methods (verbal estimation and reproduction) produced similar findings with regard to paradigm and cognitive load. In the analyses, verbal estimations of time were found to be more accurate than time reproductions. This finding is inconsistent with most of the earlier findings e.g. [17] [22]. The finding that verbal estimation produces more accurate judgments as compared to reproduction method can be explained on the basis of the task involvement and the gap between the presentation and reproduction of temporal information. Reproduction method requires active involvement in the task. This might have resulted in more errors in time judgment. In addition to this, the waiting period during the gap could have distracted the subjects from paying attention to time. Earlier studies [23]-[27] utilized only short duration for comparing verbal and reproduction methods. The present study employed long duration (150 s) to determine the effect of verbal and reproduction method on time judgment. It is quite possible that for longer durations factor such as task involvement might be important. There is a need for further research using both short- and long-duration to determine the exact role of duration in reproduction method among dyslexics.

The main objective of the current study was to find out time estimation ability among dyslexics children. Results showed that performance on time estimation of both normal and dyslexics was deteriorated. However, performance of dyslexic's children was worse than normal control group. The existing literature is of the view that dyslexics have mild dysfunction in cerebellum which causes time estimation and language problems among dyslexics [11] [12]. This is first study of its kind to investigate role paradigm, method of time estimation and duration dyslexic's population. Results of this study should, therefore, be interpreted with caution. Further studies are needed to ascertain exact nature of time estimation ability among dyslexics under different context.

\section{References}

[1] Dilling, H., Mombour, W. and Schmidt, M.H. (1991) International Classification of Mental Diseases, ICD-10. German Edition, Huber, Bern.

[2] Wise, B.W., Ring, J. and Olson, R.K. (1999) Training Phonological Awareness with and without Explicit Attention to Articulation. Journal of Experimental Child Psychology, 72, 271-304. http://dx.doi.org/10.1006/jecp.1999.2490

[3] Baddeley, A., Gathercole, Su. and Papagno, C. (1998) The Phonological Loop as a Language Learning Device. Psychological Review, 105, 158-173. http://dx.doi.org/10.1037/0033-295X.105.1.158

[4] Baddeley, A.D. (2003) Working Memory: Looking Back and Looking Forward. Nature Reviews Neuroscience, 4, 829839. http://dx.doi.org/10.1038/nrn1201

[5] Bruck, M. (1992) Persistence of Dyslexics' Phonological Awareness Deficits. Developmental Psychology, 28, 874- 
886. http://dx.doi.org/10.1037/0012-1649.28.5.874

[6] Felton, R.H., Naylor, C.E. and Wood, F.B. (1990) Neuropsychological Profile of Adult Dyslexics. Brain and Language, 39, 485-497. http://dx.doi.org/10.1016/0093-934X(90)90157-C

[7] Pennington, B.F., Orden, G.C.V., Smith, S.D., Green, P.A. and Haith, M.M. (1990) Phonological Processing Skills and Deficits in Adult Dyslexics. Child Development, 61, 1753-1778. http://dx.doi.org/10.2307/1130836

[8] Snowling, M., Nation, K., Moxham, P., Gallagher, A. and Frith, U. (1997) Phonological Processing Skills of Dyslexic Students in Higher Education: A Preliminary Report. Journal of Research in Reading, 20, 31-41. http://dx.doi.org/10.1111/1467-9817.00018

[9] Ivry, R.B. and Keele, S.W. (1989) Timing Functions of the Cerebellum. Journal of Cognitive Neuroscience, 1, 136152. http://dx.doi.org/10.1162/jocn.1989.1.2.136

[10] Ramus, F. (2003) Developmental Dyslexia: Specific Phonological Deficit or General Sensorimotor Dysfunction? Current Opinion in Neurobiology, 13, 212-218. http://dx.doi.org/10.1016/S0959-4388(03)00035-7

[11] Nicolson, R.I., Fawcett, A.J. and Dean, P. (1995) Time Estimation Deficits in Developmental Dyslexia: Evidence for Cerebellar Involvement. Proceedings of the Royal Society, 259, 43-47. http://dx.doi.org/10.1098/rspb.1995.0007

[12] Gooch, D., Snowling, M. and Hulme, C. (2011) Time Perception, Phonological Skills and Executive Function in Children with Dyslexia and/or ADHD Symptoms. Journal of Child Psychology and Psychiatry, 52, 195-203. http://dx.doi.org/10.1111/j.1469-7610.2010.02312.x

[13] Hicks, R.E., Miller, G.W. and Kinsbourne, M. (1976) Prospective and Retrospective Judgments of Time as a Function of Amount of Information Processed. American Journal of Psychology, 89, 719-730. http://dx.doi.org/10.2307/1421469

[14] Doob, L.W. (1971) Patterning of Time. Yale University Press, New Haven.

[15] Brown, S.W. (1992) Attention and Interference in Prospective and Retrospective Timing. Perception, 21, 545-557. http://dx.doi.org/10.2307/1421469

[16] Poynter, W.D. (1983) Duration Judgment and the Segmentation of Experience. Memory \& Cognition, 11, 77-82. http://dx.doi.org/10.3758/BF03197664

[17] Brown, S.W. (1985) Time Estimation and Attention: The Effects of Prospective versus Retrospective Paradigms and Task Demands on Perceived Duration. Perception \& Psychophysics, 38, 115-124. http://dx.doi.org/10.3758/BF03198848

[18] Battig, W.F. and Montague, W.E. (1969) Category Norms for Verbal Items in 56 Categories: Replication and Extension of Connecticut Category Norms. Journal of Experimental Monograph, 80, 1-46. http://dx.doi.org/10.1037/h0027577

[19] Boltz, M. (1989) Time Judgments of Musical Endings: Effects of Expectancies on the "Filled Interval Effect". Perception \& Psychophysics, 46, 409-418. http://dx.doi.org/10.1037/h0027577

[20] Boltz, M.G. (1993) Time Estimation and Expectancies. Memory \& Cognition, 21, 853-863. http://dx.doi.org/10.3758/BF03202753

[21] Zakay, D. (1989) Subjective Time and Attentional Resource Allocation: An Integrated Model of Time Estimation. In: Levin, I. and Zakay, D., Eds., Time and Human Cognition: A Life Span Perspective, Elsevier Science Publishers, North Holland, 365-397.

[22] Clausen, J. (1950) An Evaluation of Experimental Methods of Time Judgment. Journal of Experimental Psychology, 40, 756-761. http://dx.doi.org/10.1037/h0056354

[23] McClain, L. (1983) Interval Estimation: Effect of Processing Demands on Prospective and Retrospective Reports. Perception \& Psychophysics, 34, 185-189. http://dx.doi.org/10.3758/BF03211347

[24] Predebon, J. (1996) The Effect of Active and Passive Processing of Interval Events on Prospective and Retrospective Time Estimates. Acta Psychologica, 94, 41-58. http://dx.doi.org/10.1016/0001-6918(95)00044-5

[25] Predebon, J. (1999) Time Judgment as a Function of Clock Duration: Effects of Temporal Paradigm and an Attention-Demanding Non-Temporal Task. Perceptual and Motor Skills, 88, 1251-1254. http://dx.doi.org/10.2466/pms.1999.88.3c.1251

[26] Predebon, J. (2002) Viewing Distance and Estimates of Duration. Perceptual and Motor Skills, 95, 326-328. http://dx.doi.org/10.2466/pms.2002.95.1.326

[27] Predebon, J. (2002) Stimulus Motion and Retrospective Time Judgments. Acta Psychologica, 109, $213-225$. http://dx.doi.org/10.1016/S0001-6918(01)00061-0 
Scientific Research Publishing (SCIRP) is one of the largest Open Access journal publishers. It is currently publishing more than 200 open access, online, peer-reviewed journals covering a wide range of academic disciplines. SCIRP serves the worldwide academic communities and contributes to the progress and application of science with its publication.

Other selected journals from SCIRP are listed as below. Submit your manuscript to us via either submit@scirp.org or Online Submission Portal.
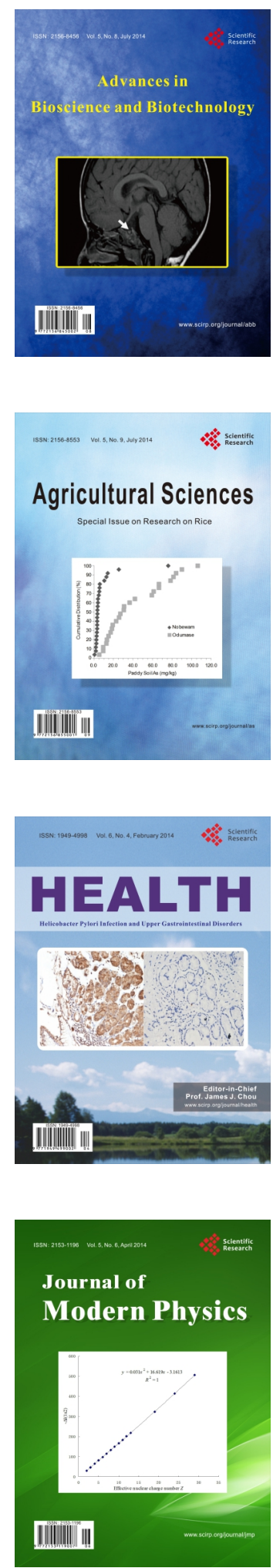
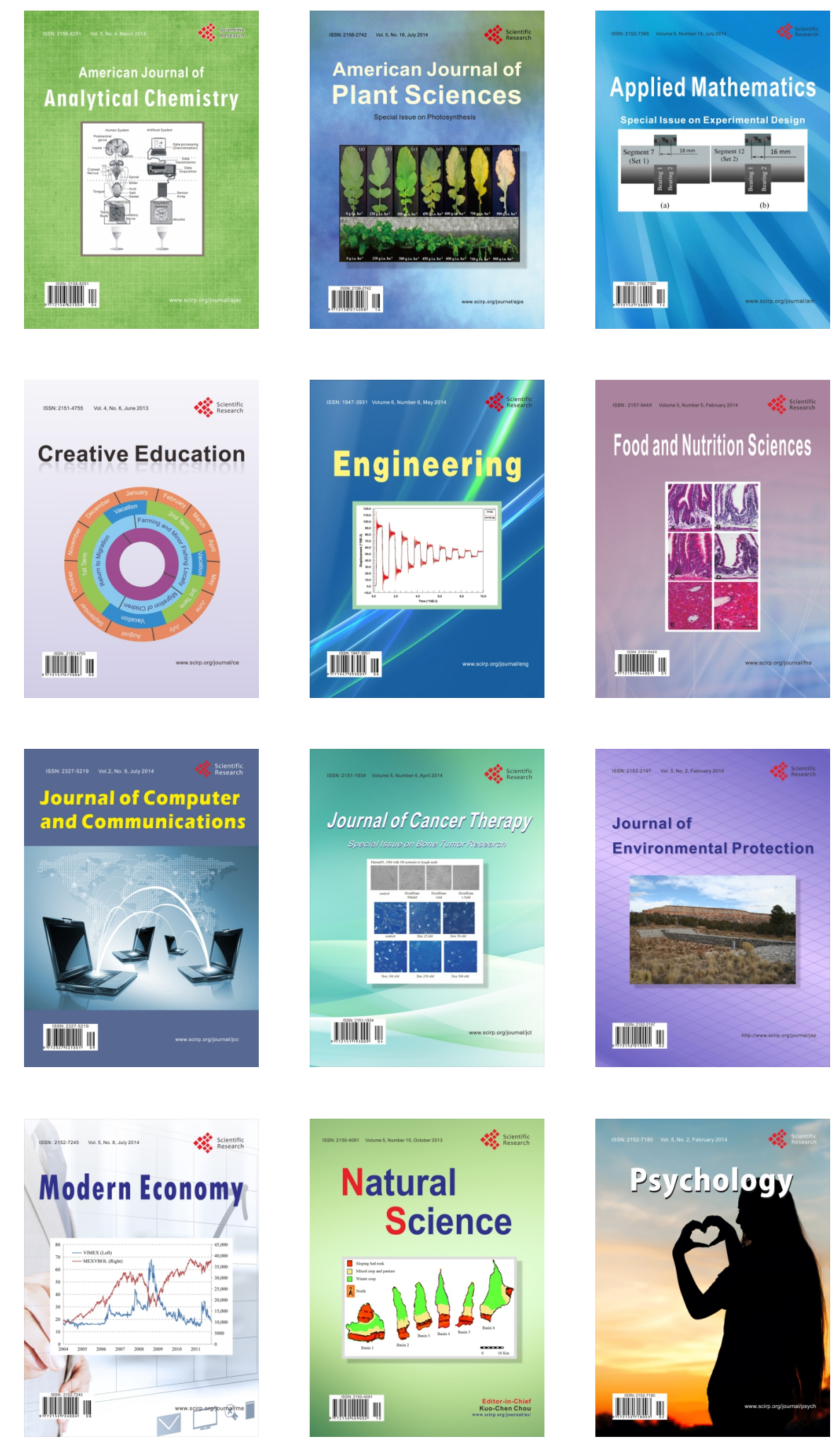